\title{
Deletion and Functional Analysis of Hepatitis B Virus X Protein: Evidence for an Effect on Cell Cycle Regulators
}

\author{
Mashael R. Al-Anazi ${ }^{a} \quad$ Nyla Nazira ${ }^{a}$ Dilek Colak ${ }^{\mathrm{b}} \quad$ Mohammed N. Al-Ahdala,c $^{a}$ \\ Ahmed A. Al-Qahtania,c \\ aDepartment of Infection and Immunity, Research Center, King Faisal Specialist Hospital \& Research \\ Center, Riyadh, bBiostatistics, Epidemiology and Scientific Computing Department, King Faisal Specialist \\ Hospital and Research Centre, Riyadh, 'Department of Microbiology and Immunology, Alfaisal \\ University School of Medicine, Riyadh, Saudi Arabia
}

\section{Key Words}

Hepatitis B virus $\cdot \mathrm{HBx} \cdot$ Cell-cycle $\bullet$ Mutants $\bullet \mathrm{HCC}$

\begin{abstract}
Background/Aims: The hepatitis $B$ virus $\mathrm{X}$ protein $(\mathrm{HBX})$ is a viral trans-activator that plays a crucial role in pathogenesis of hepatocellular carcinoma (HCC) via an unknown mechanism. The role of $\mathrm{HBx}$ in modulating cell proliferation and programmed cell death is replete with controversies. Thus, the goal of this study was to elucidate the effect of $\mathrm{HBx}$ and its deletion mutants on cell cycle progression in human hepatoma cells. Methods: Huh7 cells transfected with either full-length or truncated $\mathrm{HBx}$ were tested for their mitogenic potential based on their effect on the expression of key cell cycle-related proteins (p27, cyclin D1, p21, and p53) and pro-apoptotic proteins such as cleaved poly (ADP-ribose) polymerase (PARP) and Bax. Western blotting and immunofluorescence techniques were applied to detect changes in the expression levels and intracellular localization, respectively, of the investigated proteins. Also, Quantitative real-time PCR (qRT-PCR) was used to detect changes in RNA levels. Results: An increased anchorage-independent growth of cells transfected with HBx-WT and its deletion mutants was observed. The cell cycle regulatory molecules were differentially modulated by full-length $\mathrm{HBx}(1-154)$ and its different $\mathrm{N}$ - and C-terminal truncated forms (HBx (31-154), HBx (61-154), $\mathrm{HBx}$ (1-94), and $\mathrm{HBx}$ (61-124)). An enhanced modulation of p27, p21, and cyclin D1 was associated with $\mathrm{HBx}$ (1-154), whereas p53 expression was significantly inhibited by HBx (61-124). Similarly, the expression of cleaved PARP and Bax was efficiently suppressed by HBx (1-94) and HBx (61-154). Conclusion: The HBx-WT and its mutants play a critical role in the pathogenesis and progression of HCC by modulating cell cycle regulatory proteins.
\end{abstract}

(C) 2018 The Author(s)

Published by S. Karger AG, Basel 


\section{Introduction}

Hepatocellular carcinoma (HCC) is the sixth most common cancer and the second leading cause of cancer-related deaths in the world [1]. Approximately $50 \%$ of HCC cases worldwide are related to hepatitis B virus (HBV) [2]. In chronic HBV carriers, risk of HCC is increased by 5 - to 15-fold [3]. Currently, more than 2 billion people have been infected with HBV at some time in their lives, and approximately 240 million people remain chronically infected [4].

HBV is the prototype member of the family Hepadnaviridae. The genome of HBV consists of a 3.2-kb relaxed circular partially double-stranded DNA. HBx is a $17-\mathrm{kDa}$ regulatory protein consisting of 154 amino acids. $\mathrm{HBx}$ is a promiscuous trans-activator that modulates both viral and cellular promoters through a direct interaction with nuclear transcription factors or via cytoplasmic signal transduction [5]. The protein is shown to affect several cellular processes including reduction of adhesion of podocytes [6], modulation of apoptosis in kidney cell [7] and downregulation of microRNA-145 in HCC [8]. HBx affects cell cycle progression by inducing different signaling pathways, deregulating cell cycle checkpoints, and by protein degradation. In some established cell lines, HBx induces cell cycle progression via downregulation of cell cycle inhibitor proteins such as p21 and p27, and activation of cell cycle promoters such as cyclins D1, E, and cell division cycle 2 (CDC2) kinases [9-11]. Previous studies have reported inhibition of cell cycle progression by $\mathrm{HBx}$ via decreased expression of cyclins D1, E, A, and B1, cyclin-dependent kinase (CDK) 2 and 4, and G2/M phase arrest by activation of cyclin B1-CDK1 [11, 12]. Some studies have reported suppression of apoptosis by $\mathrm{HBx}$ through activation of nuclear factor kappa-light-chain-enhancer of activated $\mathrm{B}$ cells (NF- $\kappa B$ ), cAMP response element-binding protein (CREB) and phosphatidylinositol 3-kinase (PI3K) pathways, and survivin protein [13-15]. Other studies have shown that HBx induces apoptosis by activation of caspases and c-Jun amino-terminal kinase (JNK) pathway $[11,16]$.

Integration of HBV genomic DNA into cellular chromosomes has been observed in approximately $80-90 \%$ of HBV-related HCC, suggesting an important role of viral integration in hepatocellular carcinogenesis [17]. Truncated HBx proteins have different functional properties from those of HBx wild-type $[5,18]$, and some studies have suggested that truncated forms of HBx are more prevalent in HBV-associated tumors compared to adjacent non-tumor tissue $[19,20]$. Truncated HBx proteins are incapable of promoting apoptosis but able to promote cell proliferation [20, 21]. The study conducted by Kwun et al. have reported differential effects of HBx variants on cell cycle progression depending on their potential to regulate p21 expression [22].

The aim of this study is to gain additional insight into the pleiotropic behavior of $\mathrm{HBx}$ and its role in hepatocarcinogenesis, we generated random variants of HBx and examined their effects on the regulation of cell cycle and apoptosis in hepatoma cell line. We used full-length $\mathrm{HBx}$ and four $\mathrm{HBx}$ truncated mutants to investigate their modulatory effect on the expression of cell cycle-related proteins (p27, p21, p53, and cyclin D1) and proapoptotic proteins (cleaved poly(ADP-ribose) polymerase (PARP) and Bax) in transfected hepatocarcinoma Huh7 cells.

\section{Materials and Methods}

\section{HBV DNA extraction}

DNA was extracted from serum of one of the patients who was diagnosed with HBV (genotype D1) using Q1Amp MinElute Virus Spin kit (Qiagen, Hilden, Germany) and the extraction procedures were according to the manufacturer's instructions. The complete HBx (465 bp) was amplified by nested-PCR and the PCR conditions were as follows: $95^{\circ} \mathrm{C}$ for $10 \mathrm{~min}$, followed by 40 cycles at $94^{\circ} \mathrm{C}$ for $1 \mathrm{~min}, 62^{\circ} \mathrm{C}$ for $45 \mathrm{sec}$, and $72^{\circ} \mathrm{C}$ for $1 \mathrm{~min}$, with final elongation at $72^{\circ} \mathrm{C}$ for $7 \mathrm{~min}$. Primer sequences used for amplification of $\mathrm{HBx}$ and its mutants are given in Table 1.

\section{KARGER}




\section{Cellular Physiology Cell Physiol Biochem 2018;49:1987-1998

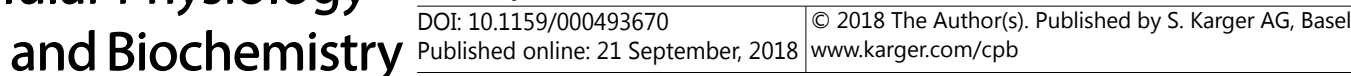

Al-Anazi et al.: The Effect of HBx Protein on the Expression of Cell Cycle Proteins

Table 1. Primer sequences used for the amplification of HBx gene and its mutants

\begin{tabular}{lrc}
\hline X gene Mutants & Forward Primer & Reverse Primer \\
\hline HBV-X (Round 1) & 5' ATT GAT TGG AAA GTM TGT M 3' & 5' TCC ACA GTA GCT CCA AAT TCT TT 3' \\
HBV-X (Round 2) & 5' CGC TTG TTT TGC TCG CAG C 3' & 5' GGC ACA GCT TGG AGG CTT G 3' \\
HBx (1-154) & 5'-CGCCTAGAATTCATGGCTGCTAGGCTGTAC-3' & 5'-TAGGCGGAATTCTTAGGCAGAGGTGAAAAAG-3' \\
HBx (31-154) & 5'-CGCCTAGAATTCATGGGGCCGCTTGGGGCTCT-3' & 5'-TAGGCGGAATTCTTAGGCAGAGGTGAAAAAG -3' \\
HBx (61-154) & 5'- CGCCTAGAATTCATGGCCTTCTCATCTGCCG-3' & 5'-TAGGCGGAATTCTTAGGCAGAGGTGAAAAAG -3' \\
HBx $(1-124)$ & 5'-CGCCTAGAATTCATGGCTGCTAGGCTGTAC -3' & 5'-TAGGCGGAATTCTTACCCCAACTCCTCCCAGT-3' \\
HBx (1-94) & 5'-CGCCTAGAATTCATGGCTGCTAGGCTGTAC -3' & 5'-TAGGCGGAATTCTTAATGTAAGACCTTGGGCA -3' \\
HBx $(61-124)$ & 5'-CGCCTAGAATTCATGGCCTTCTCATCTGCCG-3' & 5'-TAGGCGGAATTCTTACCCCAACTCCTCCCAGT-3' \\
HBx $(\Delta 31-90)$ & 5- AATCCCGCGGACGACCCTTCAAGGTCTTACAT & 5'-GTCCTCTTATGTAAGACCTTGAAGGGTCGTCCGC \\
& AAGAGGAC -3' & GGGATT -3' \\
\hline
\end{tabular}

\section{Plasmids}

The amplified PCR product of HBx was cloned into pDrive Cloning Vector using PCR cloning kit (Qiagen). The full length HBx (1-154) and its mutants (HBx (31-154) with N-terminal deletion from amino acid 1 to 30, HBx (61-154) with N-terminal deletion from amino acid 1 to 60, HBx (1-94) with a 60-amino acid C-terminal deletion, HBx (61-124) with N-terminal deletion from amino acid 1 to 60 and a 30-amino acid C-terminal deletion, and $\operatorname{HBx}(\Delta 31-90)$ with a 60-amino acid internal deletion from amino acid 31 to 90 were amplified from the above constructed clone by PCR, using specific primers (Table 1) containing EcoRI restriction site. This site matched that is found in the PEGFP-C1 vector (Clontech, Mountain View, CA, USA), which was used to create new HBx-expressing recombinant plasmids by ligation using Quick T4 DNA ligase (New England Biolabs).

\section{Cell culture and transfection}

The human hepatocarcinoma cell line Huh7 was cultured in Dulbecco's modified Eagle's medium supplemented with $10 \%$ of fetal bovine serum and $1 \%$ of antibiotic mixed solution (penicillin-streptomycin) (Invitrogen, Carlsbad, CA, USA) in $5 \% \mathrm{CO}_{2}$ at $37^{\circ} \mathrm{C}$. Huh7 cells were transfected with empty PEGFP-C1 vector, GFP/HBx wild-type, and GFP/HBx mutants using Lipofectamine 2000 (Invitrogen), according to the manufacturer's instructions. Empty PEGFP-C1 vector without HBx was used as control. Expression of HBx in transfected cells was verified by Western blot analysis.

\section{Cell transformation assay}

CytoSelect 96-well Cell Transformation Assay Kit (Cell Biolabs, San Diego, CA, USA) was used to assess the tumorigenic potential of $\mathrm{HBx}$ and its mutants based on anchorage-independent cell growth in soft agar. In brief, Huh7 cells transfected with different HBx deletion mutants were plated on soft agar in a 96-well plate and incubated for 6-8 days before being solubilized, lysed, and detected by the CyQuant® GR Dye (Molecular Probes, Eugene, OR, USA) using a fluorescence plate reader (Anthos Zenyth 3100) with an excitation wavelength of $485 \mathrm{~nm}$ and an emission wavelength of $530 \mathrm{~nm}$. The anchorage-independent cell growth was determined according to the protocol provided by the manufacturer.

\section{Western blotting}

Total protein was extracted from transfected cells using radioimmunoprecipitation assay (RIPA) lysis buffer (Sigma-Aldrich, St. Louis, MO, USA). Total protein content was determined using the Bradford assay kit (Bio-Rad, Hercules, CA, USA) according to the manufacturer's instructions at $595 \mathrm{~nm}$. For Western blot analysis, equal amount of protein samples were separated by $12 \%$ sodium dodecyl sulfate-polyacrylamide gel electrophoresis (SDS-PAGE) and transferred onto polyvinylidene difluoride (PVDF) membranes (Millipore, Billerica, MA, USA). Blots were blocked with 5\% skim milk, followed by incubation with rabbit antibodies against HBx (GenScript USA Inc., Piscataway, NJ, USA), p27, cyclin D1, p53, p21, cleaved PARP and Bax (Santa Cruz Biotechnology, Dallas, TX, USA), and glyceraldehyde-3-phosphate dehydrogenase (GAPDH) (Cell Signaling Technology, Danvers, MA, USA). Blots were incubated with secondary antibody conjugated to horseradish peroxidase and visualized by SuperSignal West Pico Chemiluminescent Substrate (Thermo Scientific, Waltham, MA, USA). 


\section{Cellular Physiology Cell Physiol Biochem 2018;49:1987-1998 and Biochemistry \begin{tabular}{l|l} 
DOI: 10.1159/000493670 & 2018 The Author(s). Published by S. Karger AG, Basel \\
(c) & www.kargercom/cpb
\end{tabular}

\section{Intracellular localization}

Huh7 cells $\left(8 \times 10^{5}\right)$ were seeded in $60 \mathrm{~mm}$ culture dishes the day before the transfection assay. Cells reached $90-95 \%$ confluence at the time of transfection. The intracellular localization of HBx was observed by fluorescence microscopy (Carl ZEISS, Oberkochen, Germany) at $24 \mathrm{~h}$ post-transfection for localization of expressed GFP/HBx wild-type and GFP/HBx mutants.

\section{Statistical analysis}

Bands in the Western blot images were quantified by Image J software (NIH Image, NIH Bethesda, USA). Calculation was performed by subtracting the background intensity from intensity of the band of interest. Each measurement was repeated in at least three independent experiments. The data was assessed as means \pm standard deviation (SD) and the student's $t$-test was used to assess the differences between means. $P$ values $<0.05$ were considered to be statistically significant. All statistical analyses were performed using Statistical Package for Social Sciences (SPSS) software (version 16, SPSS, Inc, Chicago, IL, USA).

\section{Results}

\section{Construction and expression of $\mathrm{HBx}$ mutants}

Fig. 1A shows the schematic representation of different HBx deletion mutants used in the present study. HBx-expressing recombinant plasmids were constructed with PEGFP-C1 vector and full-length $\mathrm{HBx}(1-154)$ and its mutants ( $\mathrm{HBx}$ (31-154), $\mathrm{HBx}$ (61-154), $\mathrm{HBx}$ (1-94), $\operatorname{HBx}(61-124)$, and $\operatorname{HBx}(\Delta 31-90))$. The human hepatoma cell line Huh7 was used to explore the effects of $\mathrm{HBx}$ in liver cells. Expression of green fluorescence protein (GFP)-tagged HBx

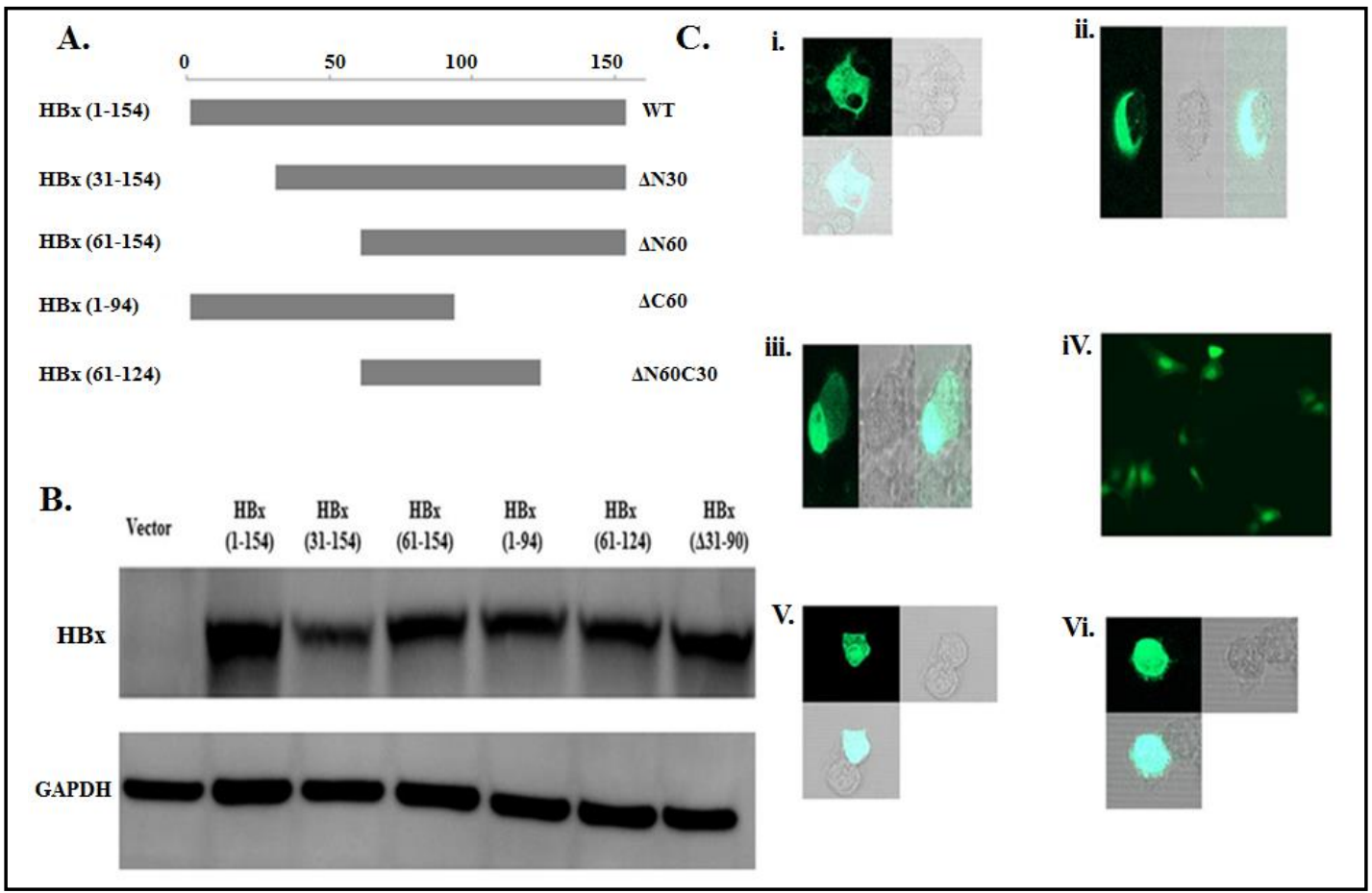

Fig. 1. Construction and expression of the HBV X protein mutants. (A) Schematic presentation of HBx (amino acids 1-154) and its deletion mutants analyzed in the present study. (B) Expression of GFP-tagged HBx proteins transiently expressed in Huh7 cell cultures. (C) Intracellular localization of HBx wild-type and mutants expressed in Huh7 cells. The intracellular expressed proteins were observed by fluorescence and confocal microscopy. (i) GFP; (ii) $\operatorname{HBx}(31-154)$; (iii) $\operatorname{HBx}(61-124)$; (iv) $\operatorname{HBx}(1-154)$; (v) $\operatorname{HBx}(61-154)$; (vi) $\operatorname{HBx}(1-94)$. The GFP and fusion proteins (i, ii, iv, v, and vi) were mainly localized to the cytoplasm except $\operatorname{HBx}(61-124)$ found mainly in the nucleus (iii). 


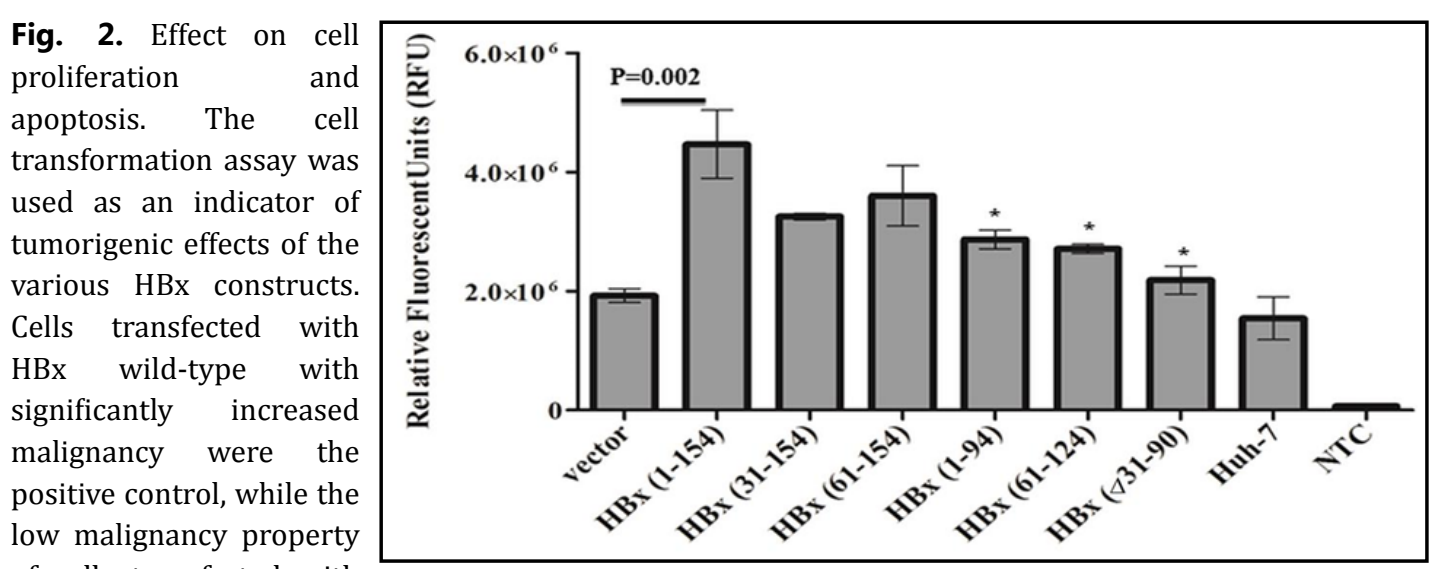
of cells transfected with PEGFP-C1 vector acted as the negative control. Untransfected Huh7 cells were also used for analysis. Horizontal bar indicates comparison between HBx wild-type and control vector. Comparisons between HBx wild-type and mutants are shown as asterisk symbols as follows: ${ }^{*} \mathrm{p}$ value $<0.05$, ${ }^{* *} \mathrm{p}$ value $<0.001$, and *** $\mathrm{p}$ value $<0.0001$.

wild-type and different deletion mutants of HBx in the Huh7 cell line was confirmed by Western blotting. Fig. 1B shows the protein expression of full-length HBx and its truncated mutants in transfected Huh7 cells. Expression of GFP/HBx wild-type and mutants in Huh7 cells was observed by fluorescence and confocal microscopy for localization of HBx proteins. GFP/HBx fusion proteins were mainly localized in the cytoplasm except the mutant GFP/ HBx (61-124), largely found in the nucleus (Fig. 1C).

\section{Effect on anchorage-independent cell growth and apoptosis}

The tumorigenic potential of the different HBx deletion mutants was estimated by cell transformation assay. The soft agar colony formation assay showed an increased colony formation in GFP/HBx wild-type compared to the empty PEGFP-C1 vector and untransfected Huh7 cells (Fig. 2). This increased anchorage-independent growth observed in cells transfected with HBx (1-154) was statistically significant $(p=0.002)$ as compared to the empty PEGFP-C1 vector and untransfected Huh7 cells (Fig. 2). The cells transfected with the HBx mutant constructs showed a range of variation in tumorigenic potential compared to HBx (1-154). The tumorigenicity of all the investigated HBx deletion mutants was less than that of HBx (1-154). HBx loss its tumorigenic effect by $\sim 80-90 \%$ after deletion of 60 aa $(\Delta 31$ 90) while the constructs HBx (61-124) and HBx (1-94) decrease by 50\% HBX tumorigenic effects. No significant variation in tumorigenic potential was observed for HBx (31-154) and HBx (61-154). These results emphasize different possible mechanisms by which HBx and its mutants influence the cell cycle progression.

\section{Effect on cell cycle regulators}

p27 and p21, two important members of the CDK interacting protein/kinase inhibitory protein (CIP/KIP) family, are cell cycle inhibitors blocking G1/S phase transition [23]. HBx (1-154) significantly decreased the expression of p27 compared to the control vector (Fig. 3A). HBx (61-154) and HBx (61-124) were less efficient in downregulating the expression of p27 compared to HBx (1-154). HBx (31-154) and HBx (1-94) did not show any significant effect on expression of p27 compared to HBx (1-154). HBx (61-154) and HBx (61-124) showed decreased ability to modulate p27 expression, whereas HBx (31-154) did not show any significant effect, suggesting that amino acids 31-60 are important for p27 expression regulation. Therefore, the degree of regulation of $\mathrm{p} 27$ expression by $\mathrm{HBx}(\Delta 31-90)$ was examined. HBx ( $\Delta 31-90)$ showed similar results as $\mathrm{HBx}$ (61-154) and $\mathrm{HBx}$ (61-124) in regulating p27, supporting the role of amino acids 31-60 in the inhibitory activity of HBx (Fig. 3A). p21 expression was the most strongly downregulated protein by HBx and its 


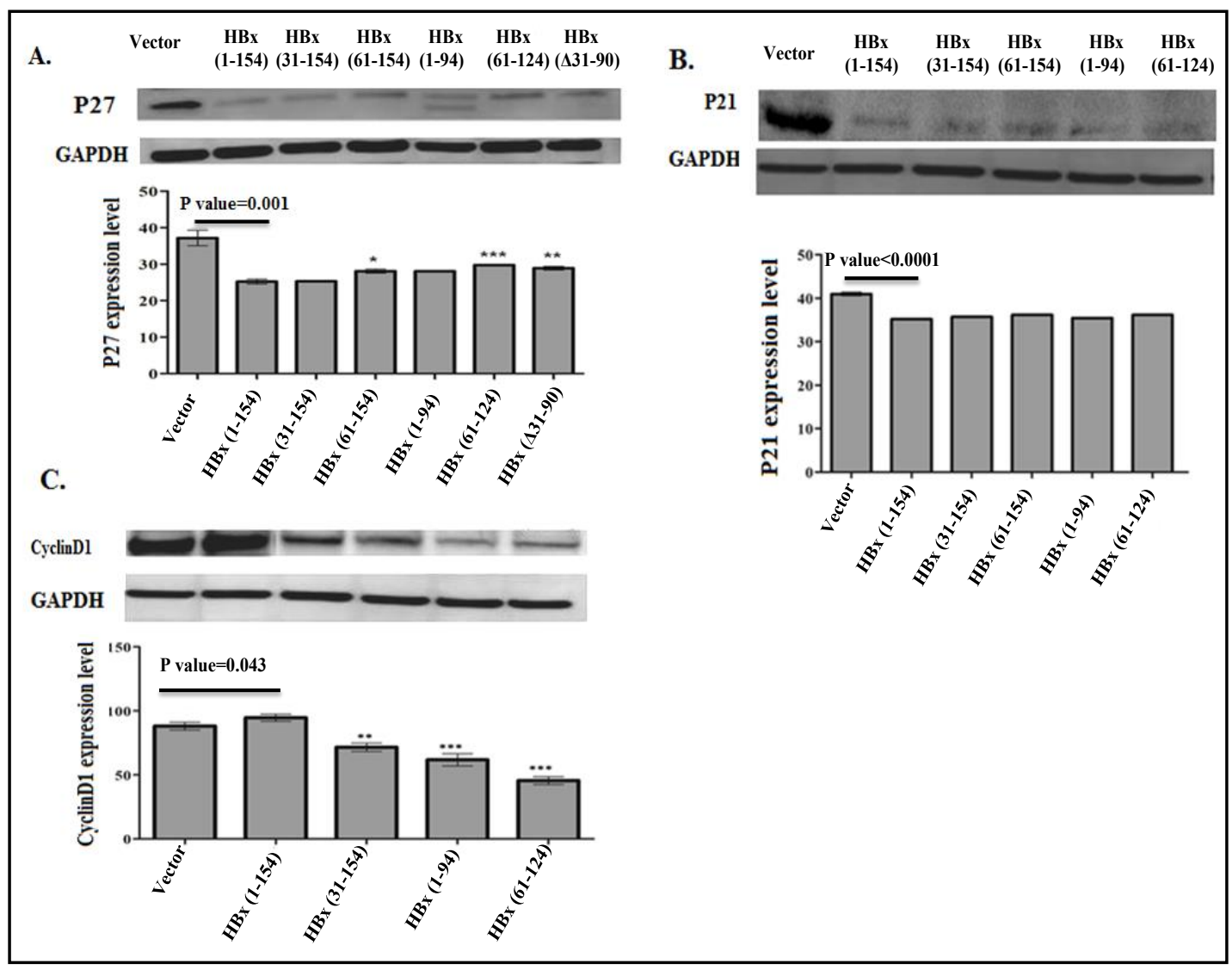

Fig. 3. Effect of HBx on cell cycle regulators as examined by Western blot analysis. (A) Expression of p27 (B) Expression of p21 and (C) Expression of cyclin D1. Huh7 cell cultures were transfected with empty PEGFP-C1 vector, GFP-tagged HBx wild-type, and GFP-tagged HBx mutants. Horizontal bar indicates comparison between HBx wild-type and control vector. Comparisons between HBx wild-type and mutants are shown as asterisk symbols as follows: ${ }^{*} \mathrm{p}$ value $<0.05,{ }^{* *} \mathrm{p}$ value $<0.001$, and ${ }^{* * *} \mathrm{p}$ value $<0.0001$.

truncated mutants with similar efficiency (Fig. 3B). Cyclin D1-CDK4 complex is active during G1 phase and has a key role in cell cycle progression. Cyclin D1 was significantly upregulated by HBx (1-154) compared to the control vector. All the truncated HBx mutants significantly decreased the expression of cyclin D1 compered to both HBx (1-154) and the control vector (Fig. 3C).

\section{Effect on $p 53$}

p53 is a tumor suppressor protein responsible for induction of apoptosis or cell cycle arrest at the G1/S transition checkpoint [24]. HBx (1-154) decreased the expression of p53 compared to the control vector (Fig. 4). HBx (31-154) and(1-94) decreased the expression of p53 to a lesser degree than HBx (1-154). HBx (61-154) and HBx (61-124) decreased the expression of p53 to a larger extent than HBx (1-154). HBx (61-124) with a truncation at both $\mathrm{N}$ - and C-terminus was the most efficient in downregulating p53 expression (Fig. 4).

\section{Effect on apoptotic mediators}

HBx is known to regulate apoptosis by modulating the expression of pro- and antiapoptotic proteins [5]. HBx (1-154), HBx (31-154), and HBx (61-154) inhibited the generated cleaved PARP when compared to the control vector (Fig. 5A). HBx (61-124) showed the most effective inhibition of PARP cleavage compared to HBx (1-154). Similarly, HBx (1-154) also suppressed the expression of pro-apoptotic factor Bax (Fig. 5B). HBx (31-154) and HBx (61- 
Fig. 4. Effect of $\mathrm{HBx}$ mutants on p53 expression. Expression of p53 in response to $\mathrm{HBx}$ wildtype and its mutants was examined by Western blot analysis. Horizontal bar indicates comparison between HBx wild-type and control vector. Comparisons between $\mathrm{HBx}$ wild-type and mutants are shown as asterisk symbols as follows: $*$ p value $<0.05$, ** $\mathrm{p}$ value $<0.001$, and $* * *$ p value < 0.0001 .
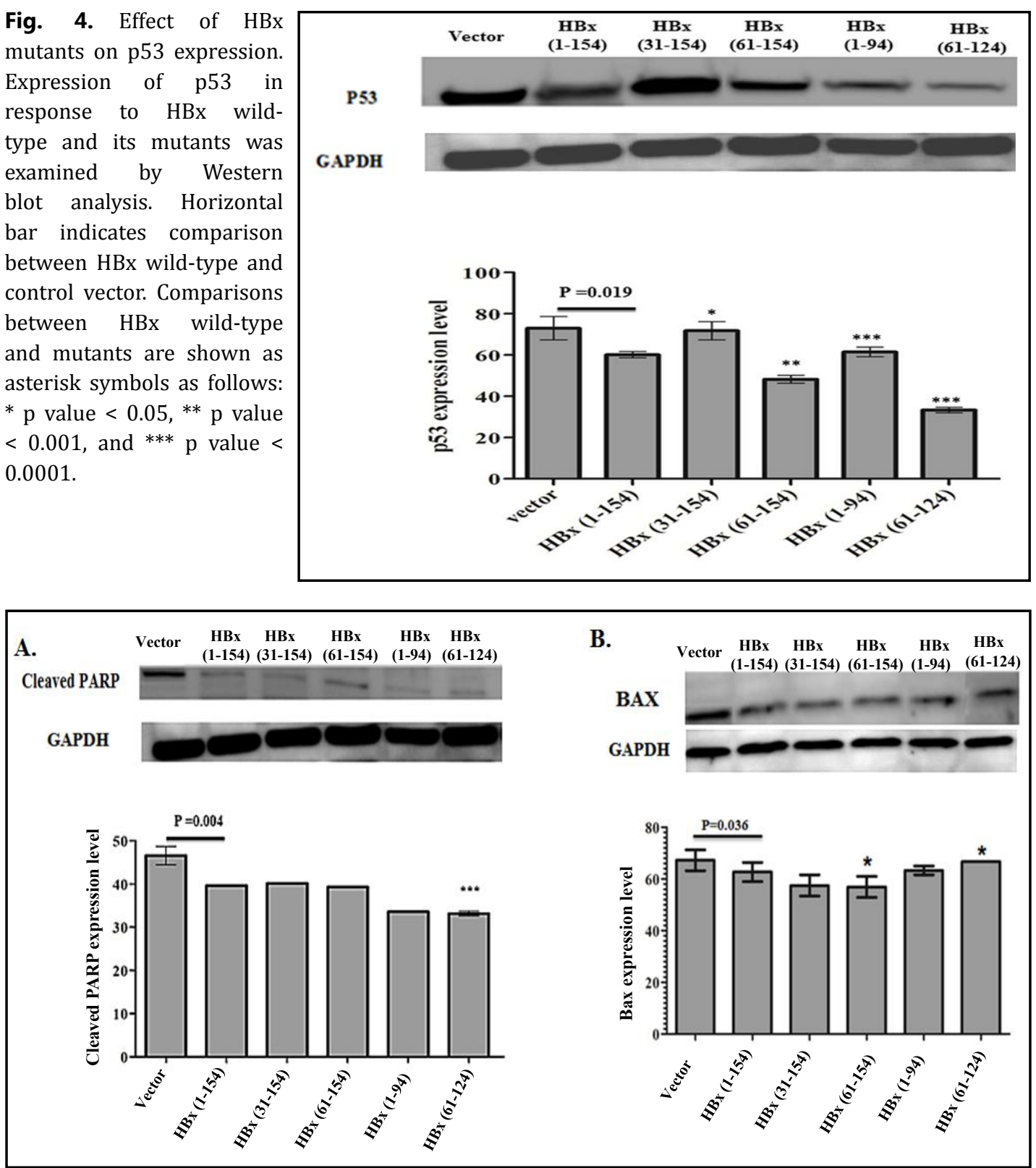

Fig. 5. Effect of HBx on apoptotic mediators. (A) Expression of cleaved poly (ADP-ribose) polymerase (PARP) and (B) Expression of Bax. The changes in expression of pro-apoptotic proteins in response to HBx wildtype and its deletion mutants were examined by Western blot analysis. Horizontal bar indicates comparison between HBx wild-type and control vector. Comparisons between HBx wild-type and mutants are shown as asterisk symbols as follows: ${ }^{*} \mathrm{p}$ value $<0.05,{ }^{* *} \mathrm{p}$ value $<0.001$, and ${ }^{* * *} \mathrm{p}$ value $<0.0001$.

154) were slightly more efficient than HBx (1-154) in decreasing Bax expression. HBx (61124) showed increased inhibitory effect on the expression of pro-apoptotic Bax (Fig. 5B).

\section{Discussion}

HBx is an HBV regulatory protein known to exert influence over a broad range of host cell functions like cell cycle progression, signaling pathways, and gene expression, contributing to oncogenic processes in HBV-related HCCs [5]. Several studies have suggested that HBx or KARGER 
its mutants are the most commonly integrated and preferentially expressed HBV genes [5, $17,25,26]$. Most studies have proposed that full-length HBx has two functional domains, $\mathrm{N}$ - and C-terminus, but there is less consensus on the regulatory role played by each domain $[5,20,27,28]$. Any deletion in the full- length HBx might alter the balance of the functional domains in regulation of cell proliferation, apoptosis, transactivation, transformation, and protein-protein interaction. This study investigated the tumorigenic potential of different HBx mutants compared to full-length HBx and identified the related changes in expression of various effector molecules involved in cell cycle progression and apoptosis. The clinical implications of such studies will bring significant increase in the effect of HBx-targeting therapeutic methods by controlling the cell cycle disrupting activities of HBx or its mutants.

In the present study, full-length $\mathrm{HBx}$ (1-154) and its mutants HBx (31-154), HBx (61154), HBx (1-94) were found mainly localized in cytoplasm. This result was consistent with previous studies which reported cytoplasmic localization of HBx, especially at high expression levels of the protein frequently observed in transient transfections [5]. Truncation at either the $\mathrm{N}$ - or the $\mathrm{C}$ - terminus did not control the cellular localization of $\mathrm{HBx}$, consistent with previous studies $[29,30]$. One of the interesting findings in this study was that the double truncation mutant HBx (61-124) with a 60-amino acid deletion at the N-terminus and a 30 -amino acid deletion at the C-terminus was found mainly in the nucleus. Some studies have reported that amino acid residues in different domains of HBx are prone to phosphorylation and other post-translational modifications, and these modifications might regulate cellular localization of HBx [31,32]. The possible reason for nuclear localization of HBx (61-124) could be that truncation at both ends might result in a conformational change in the protein either exposing a masked nuclear localization signal or increasing the possible surface accessibility of the amino acid residues for post-translational modifications and interactions with cellular proteins capable of changing the cellular localization. Alefantis et al. have reported that the localization of human T-cell leukemia virus type 1 (HTLV-1) trans-activator protein Tax was directed by specific changes in Tax or by its interactions with cellular proteins [33].

HBx causes uncontrolled cell proliferation by deregulating cell cycle checkpoints via altered expression or proteolytic degradation of cyclin-dependent kinase inhibitors $[5,10]$. The cell cycle regulators p27 and p21 are active in G1 phase but block G1/S phase transition by binding and inhibiting the cyclin E-cdk2 complex [22, 34, 35]. Mukherji et al. have reported the early proteolytic degradation of cdk2-bound p27 mediated by cdk2 phosphorylation of p27 in the presence of HBx [10]. Cdk2 has been reported to interact weakly with amino acids 58-84 of HBx but is associated with specific phosphorylation of serine-rich domain (amino acids 21-57) of HBx. In this study, HBx (61-154) and HBx (61-124) led to increased activity of HBx in modulating p27 as compared to that of HBx (1-154). This decreased activity of HBx mutants might be due to disruption of the phosphorylation site within the deleted amino acids 31-60. HBx $(\Delta 31-90)$ also showed a decrease in HBx activity. Since HBx lacks the consensus cdk2 recognition motifs, our results suggest that exclusive phosphorylation of serine-rich domain plays a role in modulating HBx effect on p27 destabilization. Several different studies have reported downregulation as well as upregulation of p21 expression by $\operatorname{HBx}[11,36,37]$. The results of the present study showed that full-length HBx and all its truncated forms significantly downregulated p21 expression with almost similar efficiency. Although other factors have been suggested to regulate p21 expression $[22,23,31,35,36$, $38,39]$, we showed that HBx downregulated the expression of $\mathrm{p} 53$, and this resulted in inhibition of downstream p21 expression by all forms of HBx, suggesting that $\mathrm{p} 21$ expression is highly dependent on $\mathrm{p} 53$. This is consistent with the reports of p53-dependent regulation of p21 expression in other viruses like human papillomavirus and hepatitis $C$ virus [35].

In the present study, p53 was downregulated by full-length HBx and all its truncated forms to a variable degree. $\mathrm{HBx}$ (61-124) included amino acids 58-119, known to be essential for signal transduction [40], while the absence of modulating $\mathrm{N}$ - and C-terminal regions might be responsible for its enhanced activity in downregulation of p53. Lee and Rho showed that the cis element of p53 promoter responsible for HBx mediated inhibition is a consensus 


\section{Cellular Physiology Cell Physiol Biochem 2018;49:1987-1998

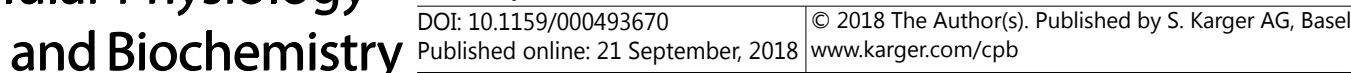

DNA sequence called E-box, which is the binding site of transcriptional regulators, including Myc, Max, and other members of basic helix-loop-helix (bHLH) protein family [41]. As HBx is known to induce c-Myc expression [42], the observed downregulation of p53 in the present study might be due to increased binding of Myc to the p53 promoter.

HBx has a controversial role in modulation of apoptosis: some studies have showed proapoptotic effects [43-47], while others have assigned an anti-apoptotic effect with a role in HCC [48-52]. Caspase 3 is a cysteine-aspartate protease responsible for cleaving various substrates, including PARP, which leads to cell apoptosis. HBx has been reported to inhibit caspase 3 activity [53]. Our results indicate that HBx (1-154), HBx (31-154), and HBx (61154) had similar inhibitory effect on expression of cleaved PARP, whereas HBx (61-124) showed significant increase in the inhibition of cleaved PARP. This was partially in agreement with Gottlob et al. that have shown that a deletion of 1-50 amino acids at the N-terminus did not have any effect on the inhibition of caspase activity [53]. Our results showed a reduction in the inhibition of caspase activity in C-terminal deletion mutants of HBx. HBx inhibits p53mediated upregulation of Fas, which has been shown to activate caspase 3 activity $[54,55]$. Our observation that p53 expression was strongly suppressed by HBx (61-154) and HBx (61-124) supported the increased inhibition of cleaved PARP expression by these mutants possibly via downregulation of Fas-mediated caspase 3 activity. Similar to our results, Tu et al. have reported that both natural and artificial mutants of HBx with a C-terminal deletion caused suppression of pro-apoptotic function [20]. Bax, a pro-apoptotic protein member of the Bcl-2 family, participates in the induction of apoptosis in response to many apoptotic signals. Also for Bax expression, the C-terminal deletion caused a suppression of proapoptotic effect of $\mathrm{HBx}$, leading to an increased inhibition of Bax by HBx (31-154) and HBx (61-254).

The role of HBx in cell regulation and pathogenesis of hepatocellular carcinoma is replete with controversial and contradictory studies. In the present study, we evaluated the effect of $\mathrm{HBx}$ and its truncated forms directly on the expression of specific cell cycle regulators. We observed that each cell cycle regulator molecule had a distinct pattern of response to different HBx forms. p27, p21, cyclin D1, p53, pro-apoptotic cleaved PARP, and Bax were better modulated by HBx (1-154), HBx (61-124), HBx (1-94), and HBx (61-124), respectively. One of the possible explanation for the reported pleiotropic effect of $\mathrm{HBx}$ on cellular regulation could be the co-existence of different forms of the HBx, as reported previously by Tu et al. [20], and a specific effect on the expression of effector molecules exerted by each HBx form. The combined effect on cellular regulation could also depend on the relative proportion of each mutant form and how efficiently the expression of regulatory proteins is modulated by HBx. The tumorigenic potential of different HBx mutants was assessed in-vitro by their ability to initiate uncontrolled growth in cells. The reduction in tumorigenic potential of HBx $(\Delta 31-90)$ supported the observed decreased activity of this mutant in modulating p27 in the present study. As shown by cell transformation assay, the tumorigenic potential of the full-length $\mathrm{HBx}$ is greater than that of the C-terminal deletion mutants, which appears to be contradictory to other results in this study. This could be explained considering that the C-terminal region spanning amino acids 141-154 decreases HBx stability [56]. The HBx C-terminal deletion mutants in HBV-infected cells have an increased stability compared to the full-length HBx and might play a more active role in the development of HCC. Our results are consistent with the previous reports of $\mathrm{C}$-terminal deletion mutants promoting cell proliferation $[28,57]$. This is further supported by several studies demonstrating the increased frequency of $\mathrm{C}$ - terminal deletions of HBx in the genome of $\mathrm{HBV}$-associated liver tumor cells [29].

\section{Conclusion}

Direct effect of full-length HBx and its truncated forms on the expression of effector molecules of cell cycle progression was observed. C-terminal deletions increased the 


\section{Cellular Physiology Cell Physiol Biochem 2018;49:1987-1998

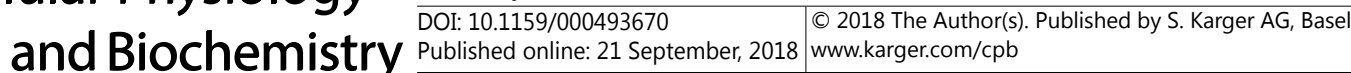

Al-Anazi et al.: The Effect of HBx Protein on the Expression of Cell Cycle Proteins

oncogenic potential of $\mathrm{HBx}$, whereas the N-terminus was essential for upregulation of cell cycle checkpoint regulators. Further studies are required to elucidate the exact mechanism of modulation by HBx and its deletion mutants.

\section{Acknowledgements}

This work was supported by King Abdulaziz City for Science and Technology (KACST), National plan for Science, Biotechnology, and Innovation (NSTIP) (Project number 11MED1430-20). This study was approved by Research Advisory Council (RAC) of King Faisal Specialist Hospital and Research Centre (KFSHRC), project number 2150008. The support of the Research Center administration at KFSHRC is highly appreciated. We would like to thank Dr. Futwan Al-Mohanna for his excellent help with confocal microscopy.

\section{Disclosure Statement}

The authors declare that there are no conflicts of interest.

\section{References}

1 Bray F, Ren JS, Masuyer E, Ferlay J: Global estimates of cancer prevalence for 27 sites in the adult population in 2008. Int J Cancer 2013;132:1133-1145.

-2 El-Serag HB: Epidemiology of viral hepatitis and hepatocellular carcinoma. Gastroenterology 2012;142:1264-1273 e1261.

-3 Tsai WL, Chung RT: Viral hepatocarcinogenesis. Oncogene 2010;29:2309-2324.

$4 \quad$ Organization, World Health: Hepatitis B factsheet $N^{\circ} 204$.

-5 Bouchard MJ, Schneider RJ: The enigmatic X gene of hepatitis B virus. J Virol 2004;78:12725-12734.

-6 He P, Zhang B, Liu D, Bian X, Li D, Wang Y, Sun G, Zhou G: Hepatitis B Virus X Protein Modulates Apoptosis in NRK-52E Cells and Activates Fas/FasL Through the MLK3-MKK7-JNK3 Signaling Pathway. Cell Physiol Biochem 2016;39:1433-1443.

7 He P, Liu D, Zhang B, Zhou G, Su X, Wang Y, Li D, Yang X: Hepatitis B Virus X Protein Reduces Podocyte Adhesion via Downregulation of alpha3beta1 Integrin. Cell Physiol Biochem 2017;41:689-700.

8 Gao F, Sun X, Wang L, Tang S, Yan C: Downregulation of MicroRNA-145 Caused by Hepatitis B Virus X Protein Promotes Expression of CUL5 and Contributes to Pathogenesis of Hepatitis B Virus-Associated Hepatocellular Carcinoma. Cell Physiol Biochem 2015;37:1547-1559.

-9 Park SH, Jung JK, Lim JS, Tiwari I, Jang KL: Hepatitis B virus X protein overcomes all-trans retinoic acidinduced cellular senescence by downregulating levels of p16 and p21 via DNA methylation. J Gen Virol 2011;92:1309-1317.

10 Mukherji A, Janbandhu VC, Kumar V: HBx-dependent cell cycle deregulation involves interaction with cyclin E/A-cdk2 complex and destabilization of p27Kip1. Biochem J 2007;401:247-256.

11 Yang $\mathrm{CH}$, Cho M: Hepatitis B virus X gene differentially modulates cell cycle progression and apoptotic protein expression in hepatocyte versus hepatoma cell lines. J Viral Hepat 2013;20:50-58.

$>12$ Cheng P, Li Y, Yang L, Wen Y, Shi W, Mao Y, Chen P, Lv H, Tang Q, Wei Y: Hepatitis B virus X protein (HBx) induces G2/M arrest and apoptosis through sustained activation of cyclin B1-CDK1 kinase. Oncol Rep 2009;22:1101-1107.

13 Liu Q, Chen J, Liu L, Zhang J, Wang D, Ma L, He Y, Liu Y, Liu Z, Wu J: The X protein of hepatitis B virus inhibits apoptosis in hepatoma cells through enhancing the methionine adenosyltransferase 2A gene expression and reducing S-adenosylmethionine production. J Biol Chem 2011;286:17168-17180.

14 Lee YI, Kang-Park S, Do SI, Lee YI: The hepatitis B virus-X protein activates a phosphatidylinositol 3-kinasedependent survival signaling cascade. J Biol Chem 2001;276:16969-16977.

15 Marusawa H, Matsuzawa S, Welsh K, Zou H, Armstrong R, Tamm I, Reed JC: HBXIP functions as a cofactor of survivin in apoptosis suppression. EMBO J 2003;22:2729-2740. 


\section{Cellular Physiology Cell Physiol Biochem 2018:49:1987-1998

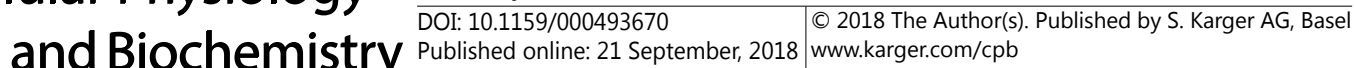

-16 Ping He BZ, Dajun Liu, Xiaohui Bian, Detian Li, Yanqiu Wang,, Guangping Sun GZ: Hepatitis B Virus X Protein Modulates Apoptosis in NRK-52E Cells and Activates Fas/FasL Through the MLK3-MKK7-JNK3 Signaling Pathway. Cell Physiol Biochem 2016;39:1433-1443.

17 Wang Y, Lau SH, Sham JS, Wu MC, Wang T, Guan XY: Characterization of HBV integrants in 14 hepatocellular carcinomas: association of truncated X gene and hepatocellular carcinogenesis. Oncogene 2004;23:142148.

18 Fu X, Tan D, Hou Z, Hu Z, Liu G, Ouyang Y, Liu F: The effect of miR-338-3p on HBx deletion-mutant (HBx-d382) mediated liver-cell proliferation through CyclinD1 regulation. PLoS One 2012;7:e43204.

19 Liu XH, Lin J, Zhang SH, Zhang SM, Feitelson MA, Gao HJ, Zhu MH: COOH-terminal deletion of HBx gene is a frequent event in HBV-associated hepatocellular carcinoma. World J Gastroenterol 2008;14:1346-1352.

-20 Tu H, Bonura C, Giannini C, Mouly H, Soussan P, Kew M, Paterlini-Brechot P, Brechot C, Kremsdorf D: Biological impact of natural $\mathrm{COOH}$-terminal deletions of hepatitis B virus X protein in hepatocellular carcinoma tissues. Cancer Res 2001;61:7803-7810.

21 Iavarone M, Trabut JB, Delpuech O, Carnot F, Colombo M, Kremsdorf D, Brechot C, Thiers V: Characterisation of hepatitis B virus X protein mutants in tumour and non-tumour liver cells using laser capture microdissection. J Hepatol 2003;39:253-261.

22 Kwun HJ, Jang KL: Natural variants of hepatitis B virus X protein have differential effects on the expression of cyclin-dependent kinase inhibitor p21 gene. Nucleic Acids Res 2004;32:2202-2213.

23 Abukhdeir AM, Park BH: P21 and p27: roles in carcinogenesis and drug resistance. Expert Rev Mol Med 2008;10:e19.

24 Giono LE, Manfredi JJ: The p53 tumor suppressor participates in multiple cell cycle checkpoints. J Cell Physiol 2006;209:13-20.

25 Rawat S, Clippinger AJ, Bouchard MJ: Modulation of apoptotic signaling by the hepatitis B virus X protein. Viruses 2012;4:2945-2972.

-26 Unsal H, Yakicier C, Marcais C, Kew M, Volkmann M, Zentgraf H, Isselbacher KJ, Ozturk M: Genetic heterogeneity of hepatocellular carcinoma. Proc Natl Acad Sci U S A 1994;91:822-826.

27 Murakami S, Cheong JH, Kaneko S: Human hepatitis virus X gene encodes a regulatory domain that represses transactivation of X protein. J Biol Chem 1994;269:15118-15123.

28 Ma NF, Lau SH, Hu L, Xie D, Wu J, Yang J, Wang Y, Wu MC, Fung J, Bai X, Tzang CH, Fu L, Yang M, Su YA, Guan $\mathrm{XY}$ : $\mathrm{COOH}$-terminal truncated HBV X protein plays key role in hepatocarcinogenesis. Clin Cancer Res 2008;14:5061-5068.

29 Lizzano RA, Yang B, Clippinger AJ, Bouchard MJ: The C-terminal region of the hepatitis B virus X protein is essential for its stability and function. Virus Res 2011;155:231-239.

-30 Li SK, Ho SF, Tsui KW, Fung KP, Waye MY: Identification of functionally important amino acid residues in the mitochondria targeting sequence of hepatitis B virus X protein. Virology 2008;381:81-88.

31 Noh EJ, Jung HJ, Jeong G, Choi KS, Park HJ, Lee CH, Lee JS: Subcellular localization and transcriptional repressor activity of HBx on p21(WAF1/Cip1) promoter is regulated by ERK-mediated phosphorylation. Biochem Biophys Res Commun 2004;319:738-745.

32 Hernandez S, Venegas M, Brahm J, Villanueva RA: The viral transactivator HBx protein exhibits a high potential for regulation via phosphorylation through an evolutionarily conserved mechanism. Infect Agent Cancer 2012;7:27.

-33 Alefantis T, Barmak K, Harhaj EW, Grant C, Wigdahl B: Characterization of a nuclear export signal within the human T cell leukemia virus type I transactivator protein Tax. J Biol Chem 2003;278:21814-21822.

34 Gearhart TL, Bouchard MJ: The hepatitis B virus X protein modulates hepatocyte proliferation pathways to stimulate viral replication. J Virol 2010;84:2675-2686.

35 Gartel AL, Radhakrishnan SK: Lost in transcription: p21 repression, mechanisms, and consequences. Cancer Res 2005;65:3980-3985.

-36 Ahn JY, Chung EY, Kwun HJ, Jang KL: Transcriptional repression of p21 (waf1) promoter by hepatitis B virus X protein via a p53-independent pathway. Gene 2001;275:163-168.

-37 Han J, Yoo HY, Choi BH, Rho HM: Selective transcriptional regulations in the human liver cell by hepatitis B viral X protein. Biochem Biophys Res Commun 2000;272:525-530.

- 38 Elmore LW, Hancock AR, Chang SF, Wang XW, Chang S, Callahan CP, Geller DA, Will H, Harris CC: Hepatitis B virus X protein and p53 tumor suppressor interactions in the modulation of apoptosis. Proc Natl Acad Sci U S A 1997;94:14707-14712. 


\section{Cellular Physiology Cell Physiol Biochem 2018;49:1987-1998

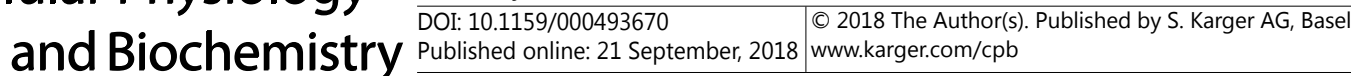 \\ Al-Anazi et al.: The Effect of HBx Protein on the Expression of Cell Cycle Proteins}

-39 Gartel AL, Tyner AL: Transcriptional regulation of the p21 (WAF1/CIP1) gene. Exp Cell Res 1999;246:280289.

-40 Nijhara R, Jana SS, Goswami SK, Kumar V, Sarkar DP: An internal segment (residues 58-119) of the hepatitis $B$ virus X protein is sufficient to activate MAP kinase pathways in mouse liver. FEBS Lett 2001;504:59-64.

41 Lee SG, Rho HM: Transcriptional repression of the human $\mathrm{p} 53$ gene by hepatitis B viral X protein. Oncogene 2000;19:468-471.

42 Li W, Miao X, Qi Z, Zeng W, Liang J, Liang Z: Hepatitis B virus X protein upregulates HSP90alpha expression via activation of c-Myc in human hepatocarcinoma cell line, HepG2. Virol J 2010;7:45.

$\$ 43$ Kim SY, Kim JK, Kim HJ, Ahn JK: Hepatitis B virus X protein sensitizes UV-induced apoptosis by transcriptional transactivation of Fas ligand gene expression. IUBMB life 2005;57:651-658.

44 Lin N, Chen HY, Li D, Zhang SJ, Cheng ZX, Wang XZ: Apoptosis and its pathway in X gene-transfected HepG2 cells. World J Gastroenterol 2005;11:4326-4331.

45 Miao J, Chen GG, Chun SY, Lai PP: Hepatitis B virus X protein induces apoptosis in hepatoma cells through inhibiting Bcl-xL expression. Cancer Lett 2006;236:115-124.

46 Su F, Theodosis CN, Schneider RJ: Role of NF-kappaB and myc proteins in apoptosis induced by hepatitis B virus HBx protein. J Virol 2001;75:215-225.

47 Koike K, Moriya K, Yotsuyanagi H, Iino S, Kurokawa K: Induction of cell cycle progression by hepatitis B virus HBx gene expression in quiescent mouse fibroblasts. J Clin Invest 1994;94:44-49.

-48 Shih WL, Kuo ML, Chuang SE, Cheng AL, Doong SL: Hepatitis B virus X protein inhibits transforming growth factor-beta -induced apoptosis through the activation of phosphatidylinositol 3-kinase pathway. J Biol Chem 2000;275:25858-25864.

49 Cheng AS, Wong N, Tse AM, Chan KY, Chan KK, Sung JJ, Chan HL: RNA interference targeting HBx suppresses tumor growth and enhances cisplatin chemosensitivity in human hepatocellular carcinoma. Cancer Lett 2007;253:43-52.

50 Murata M, Matsuzaki K, Yoshida K, Sekimoto G, Tahashi Y, Mori S, Uemura Y, Sakaida N, Fujisawa J, Seki T, Kobayashi K, Yokote K, Koike K, Okazaki K: Hepatitis B virus X protein shifts human hepatic transforming growth factor (TGF)-beta signaling from tumor suppression to oncogenesis in early chronic hepatitis B. Hepatology 2009;49:1203-1217.

51 Shih WL, Kuo ML, Chuang SE, Cheng AL, Doong SL: Hepatitis B virus X protein activates a survival signaling by linking SRC to phosphatidylinositol 3-kinase. J Biol Chem 2003;278:31807-31813.

52 Wu BK, Li CC, Chen HJ, Chang JL, Jeng KS, Chou CK, Hsu MT, Tsai TF: Blocking of G1/S transition and cell death in the regenerating liver of Hepatitis B virus X protein transgenic mice. Biochem Biophys Res Commun 2006;340:916-928.

53 Gottlob K, Pagano S, Levrero M, Graessmann A: Hepatitis B virus X protein transcription activation domains are neither required nor sufficient for cell transformation. Cancer Res 1998;58:3566-3570.

54 Wang XW, Gibson MK, Vermeulen W, Yeh H, Forrester K, Sturzbecher HW, Hoeijmakers JH, Harris CC: Abrogation of p53-induced apoptosis by the hepatitis B virus X gene. Cancer Res 1995;55:6012-6016.

55 Mannick JB, Hausladen A, Liu L, Hess DT, Zeng M, Miao QX, Kane LS, Gow AJ, Stamler JS: Fas-induced caspase denitrosylation. Science 1999;284:651-654.

-56 Li H, Chi CY, Lee S, Andrisani OM: The mitogenic function of hepatitis B virus X protein resides within amino acids 51 to 140 and is modulated by N- and C-terminal regulatory regions. J Virol 2006;80:1055410564.

57 Sirma H, Giannini C, Poussin K, Paterlini P, Kremsdorf D, Brechot C: Hepatitis B virus X mutants, present in hepatocellular carcinoma tissue abrogate both the antiproliferative and transactivation effects of $\mathrm{HBx}$. Oncogene 1999;18:4848-4859. 